\title{
ASPECTOS DA MIOCARDITE EM CHAGÁSICOS CRÔNICOS COM "MEGAS" E SEM "MEGAS" COM INSUFICIÊNCIA CARDÍACA CONGESTIVA
}

\author{
Hipólito de Oliveira Almeida, Helenice Gobbi, Vicente de Paula Antunes Teixeira, \\ Waldir Ferreira Araujo e Paula Ávila Fernandes
}

\begin{abstract}
O estudo microscópico de 20 corações de chagásicos com "megas" e de outros 20 sem "megas" com insuficiência cardíaca congestiva (ICC) revelou que tanto a fibrose quanto o exsudato inflamatório no miocárdio são discretos nos casos de "megas" $e$ geralmente acentuados nos casos de ICC. Considerando-se que nos "megas" a ICC, a hipertrofia do miocárdio e a lesão vorticilar são fenômenos raros, nossos achados (atuais $e$ anteriores) sugerem que estes estejam relacionados principalmente com a agressão inflamatória ao miocárdio ventricular, uma vez que a desnervação é, geralmente, mais acentuada nos casos de "megas" que nos de ICC.
\end{abstract}

Palavras chaves: Cardiopatia chagásica. Miocardite. Megas, Insuficiência cardíaca. Patogênese.

Desde a sua descoberta por Carlos Chagas, a doença que leva seu nome tem sido objeto de numerosos estudos. Através desses ficaram bem caracterizadas as manifestações cardiacas e digestivas como as mais freqüentes desta protozoose e o comprometimento do sistema nervoso autônomo como achado proeminente e comum a ambas as localizações. Permanecem, no entanto, ainda obscuras as relações entre a neuropatologia autônomica chagásica e algumas de suas repercussões funcionais. Tal é verdade, especialmente, para a cardiopatia, onde as teorias "neurogênica" (parassimpaticopriva) e "inflamatória" (miocardiopatia inflamatória) disputam a primazia na determinação da insuficiéncia cardiaca (ICC), da morte súbita, bem como de alterações anatômicas do coração, particularmente a hipertrofia do miocárdio e a "lesão vorticilar" (lesão da ponta ou aneurisma apical).

Despertados pelos estudos de Rezende e Rassi 28 e de Prata 27 mostrando que a insuficiência cardiaca é pouco freqüente nos casos de "megas", iniciamos uma série de estudos comparando chagásicos com e sem "megas", no sentido de ampliar as observações já existentes e tentar explicar as diferenças observadas. Até o momento estes estudos mostraram que no chagásico com "megas", além de pouco freqüente e tardia a ICC 24 , o coração é mais

Trabalho da Disciplina de Patologia Geral da Faculdade de Medicina do Triângulo Mineiro, Uberaba, Minas Gerais, Brasil.

Recebido para publicação em 7/12/83. desnervado 6 e hipertrofia-se até um grau muito inferior ao dos chagásicos sem "megas" 4 . Mostramos também que a lesão vorticilar e as tromboses intracardiacas são pouco freqüentes nos chagásicos com visceromegalias 25 . Pelos estudos realizados, podemos admitir que a desnervação não seja responsável pela insuficiência cardiaca, pela hipertrofia do miocárdio e pela lesão vorticilar, uma vez que ela é mais acentuada nos coraçōes de chagásicos com "megas" onde tais fenômenos são pouco freqüentes.

Dando prosseguimento a esta linha de estudo, analisaremos comparativamente as alterações inflamatórias do miocárdio em chagásicos com "megas" e sem "megas" com ICC.

\section{MATERIAL E MÉTODOS}

Foram estudados 40 corações de chagásicos crônicos, sendo 20 portadores de "megas" e 20 cardiopatas sem "megas" falecidos após periodo variável de ICC. Em cada coração foi feito estudo microscópico de cortes histológicos de diferentes regiões dos átrios e dos ventrículos. As colorações usadas foram hematoxilina-eosina (HE) e Giemsa. O exsudato inflamatório e a fibrose no miocárdio foram classificadas em ausentes, discretos, moderados e acentuados.

\section{RESULTADOS}

Coração de chagásicos com "megas". O exame microscópico revelou que a maioria absoluta dos corações de chagásicos com "megas" apresenta áreas 
Almeida HO, Gobbi H, Teixeira VPA, Araujo WF, Fernandes PA. Aspectos da miocardite em chagásicos crônicos com “megas" e sem "megas" com insuficiencia cardiaca congestiva. Revista da Sociedade Brasileira de Medicina Tropical 17: 8188, Abr-Jun, 1984

ou focos de miocardite, pelo menos em uma de suas câmaras. Em apenas um caso (1120) o exame microscópico foi negativo para miocardite em todos os fragmentos examinados. De modo geral a inflamação não se distribui de maneira uniforme nos diversos setores do coração, sendo mais freqüente no ventriculo esquerdo que nas demais câmaras. A miocardite está representada principalmente por focos de infiltrado mononuclear, só excepcionalmente associados a eosinófilos e mastócitos, contendo pequenos linfócitos e células da linhagem plasmocitária. Com freqüência, os plasmócitos são abundantes. Este exsudato é geralmente focal, discreto, podendo entretanto, ser acentuado em pequeno número de casos. A fibrose colágena, quando presente, é discreta e só excepcionalmente acentuada, geralmente focal e associada ao exsudato mononuclear, raramente existindo como lesão isolada sem sinais de atividade inflamatória. A observação de granulomas foi rara, não diferindo qualitativamente daqueles vistos nos casos de ICC. As miocélulas eram normais em sua maioria, raramente apresentando fenômenos "regressivos". Estes quando presentes geralmente se associavam ao exsudato inflamatório (Figs. 1 e 2).

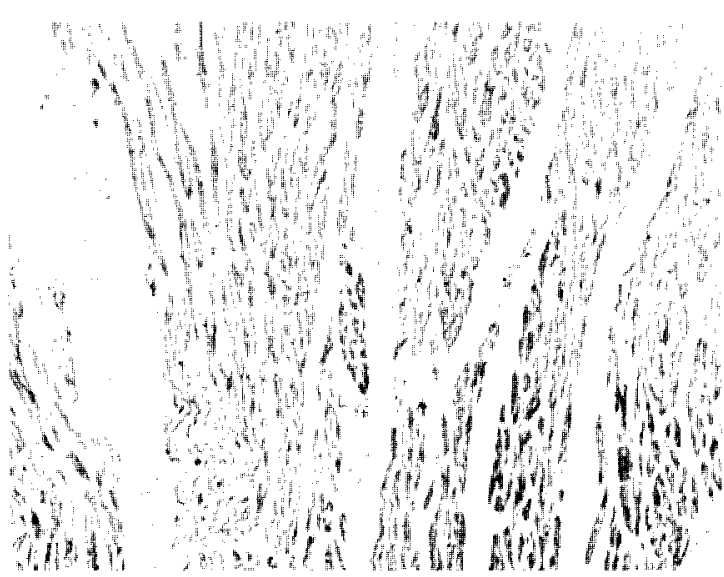

Fig 1 -Corte de ventriculo (HE x25) de chagásico com megaesôfago: observa-se apenas discreto exsudato celular focal.
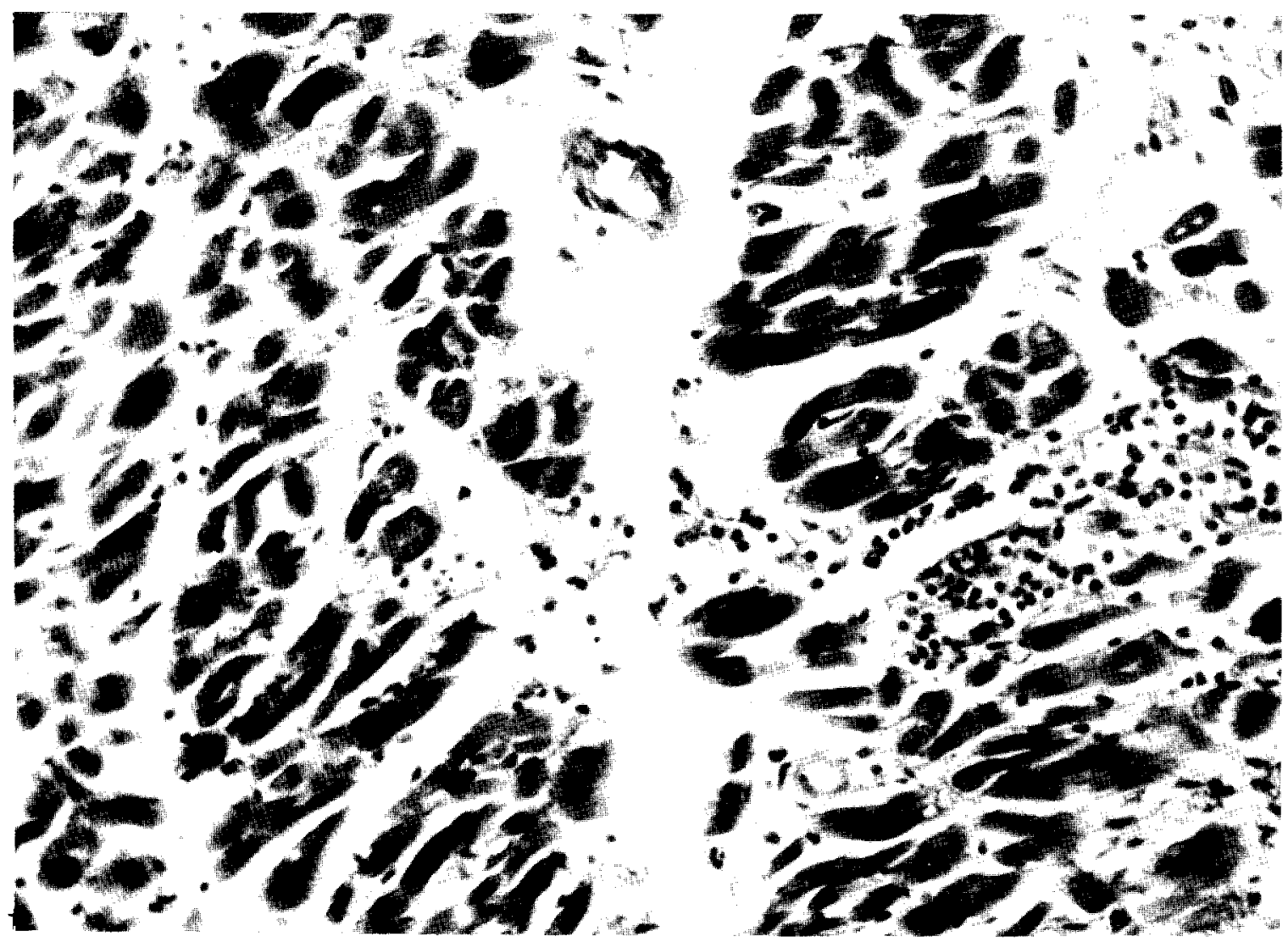

Fig. 2 - Corte de ventriculo de chagásico com megaesôfago e megacolon (tricrômico de Gomory x160). Pequeno foco de exsudato mononuclear, discreta dissociação das miocélulas. Não há fibrose evidente. 
Almeida HO, Gobbi H, Teixeira VPA, Araujo WF, Fernandes PA. Aspectos da miocardite em chagásicos crónicos com "megas" e sem "megas" com insuficiência cardiaca congestiva. Revista da Sociedade Brasileira de Medicina Tropical 17: 8188, Abr-Jun, 1984

Nos chagásicos falecidos em ICC. O exame microscópico dos corações revelou sempre alterações em todas as câmaras sendo o miocárdio ventricular, geralmente, o mais lesado. Além de congestão vênulocapilar e dilatação de canais linfáticos, os quais podem conter mononucleares, foi freqüente o edema intersticial, representado por dissociação das miocélulas e do componente fibroso do estroma e, por vezes, depósitos de material amorfo, acidófilo. Leucocitose venular focal, às vezes contendo eosinófilos associados a mononucleares, embora pouco exuberante, foi achado freqüente. $O$ exsudato celular, às vezes variando de um campo microscópico para outro, pode ser exclusivamente mononuclear, ora rico em pequenos linfócitos, ora predominando células da linhagem plasmocitária, quase sempre associadas a macrófagos. Podemos encontrar granulócitos associados, às vezes com predomínio de eosinófilos, particularmente relacionados a alteraçôes graves das miocélulas. Outra célula constante nas áreas de inflamação e o mastócito, podendo ai ser abundante. Este exsudato celular distribui-se em densos focos, predominantemente intrafasciculares, cujas miocélulas mostram-se destruidas ou lesadas, podendo no entanto, ser endomisial difuso em algumas áreas. Embora alguns poucos casos de ICC mostrassem edema e exsudato celular intensos, com desorganização fascicular e fenômenos regressivos abundantes com escassa fibrose, esta era exuberante na maioria dos casos. Embora disseminada nos ventrículos, freqüentemente era menos intenso na musculatura superficial dos dois terços superiores do ventriculo esquerdo e, em geral, acompanhava o exsudato celular descrito. Esta fibrose, caracteristicamente intrafascicular, em parte focal, formando pequenos "calos" por vezes confluentes e às vezes tomando aspecto endomisial com formação de rigido esqueleto que encarcera cada fibra muscular $\mathrm{e}$ isola-as umas das outras. Hiailinização total ou miocitólise e edema intracelular (degeneração hidrópica), foram observadas em relação topográfica com a fibrose, com o exsudato inflamatório ou à distância de ambos. Necrose de células musculares com homogeinizaçào e fragmentação do citoplasma, freqüentemente foi observado nos focos inflamatórios mais "explosivos", particularmente nos ricos em granulócitos eosinófilos. Células hipertróficas com núcleo volumoso, às vezes hipercromático e bizarro, ou hipotróficas, foram observadas, as primeiras mais freqüentemente. A reação inflamatória granulomatosa, geralmente identificada quando se examina vários cortes, foi mais freqüente nos casos de ICC que nos casos de "megas". A maioria destes granulomas mostra-se constituída por uma ou mais células gigantes associadas a mononucleares. Diferentes aspectos podem ser observados, inclusive a colagenização destes granulomas (Figs. 3 a 7). As Tabelas 1 e 2 mostram como se comportam o infiltrado leucocitário e a fibrose no miocárdio de chagásicos crônicos com "megas" e com ICC sem "megas".

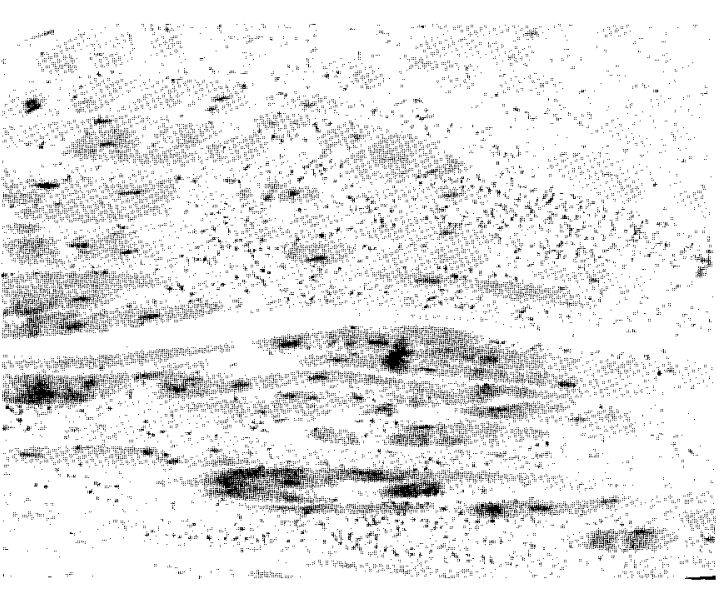

Fig. 3 - Corte de ventriculo de chagásico com ICC sem megas que evoluiu em poucos meses para óbito. Há acentuada reação inflamatória com exsudação exuberante.

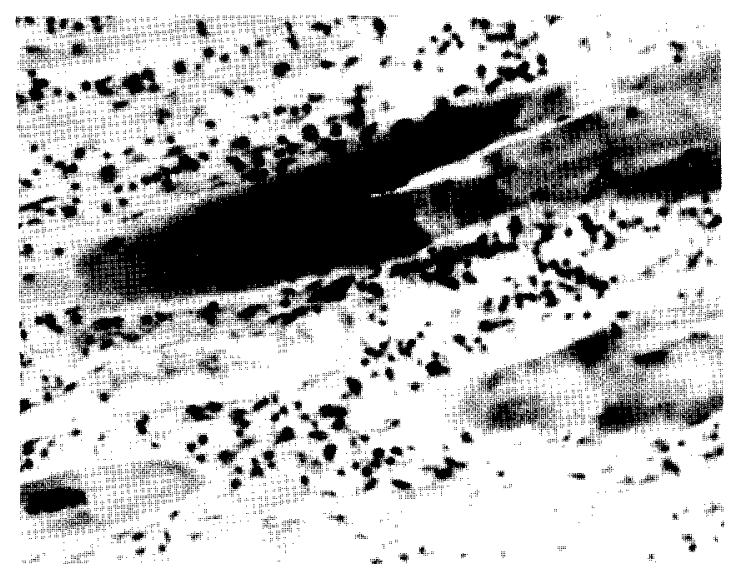

Fig. 4 - Mesmo caso da Fig. 3 (x 400). Embora a fibrose seja pouco intensa, a atividade inflamatória é exuberante e se caracteriza por intensa dissociação das fibras pelo edema e infiltrado constituído por mononucleares, granulócitos e eosinófilos. Há degeneração e destruição de miocélulas. 
Almeida HO, Gobbi H, Teixeira VPA, Araujo WF, Fernandes PA. Aspectos da miocardite em chagásicos crônicos com "megas" e sem "megas" com insuficiência cardiaca congestiva. Revista da Sociedade Brasileira de Medicina Tropical 17: 8188, Abr-Jun, 1984
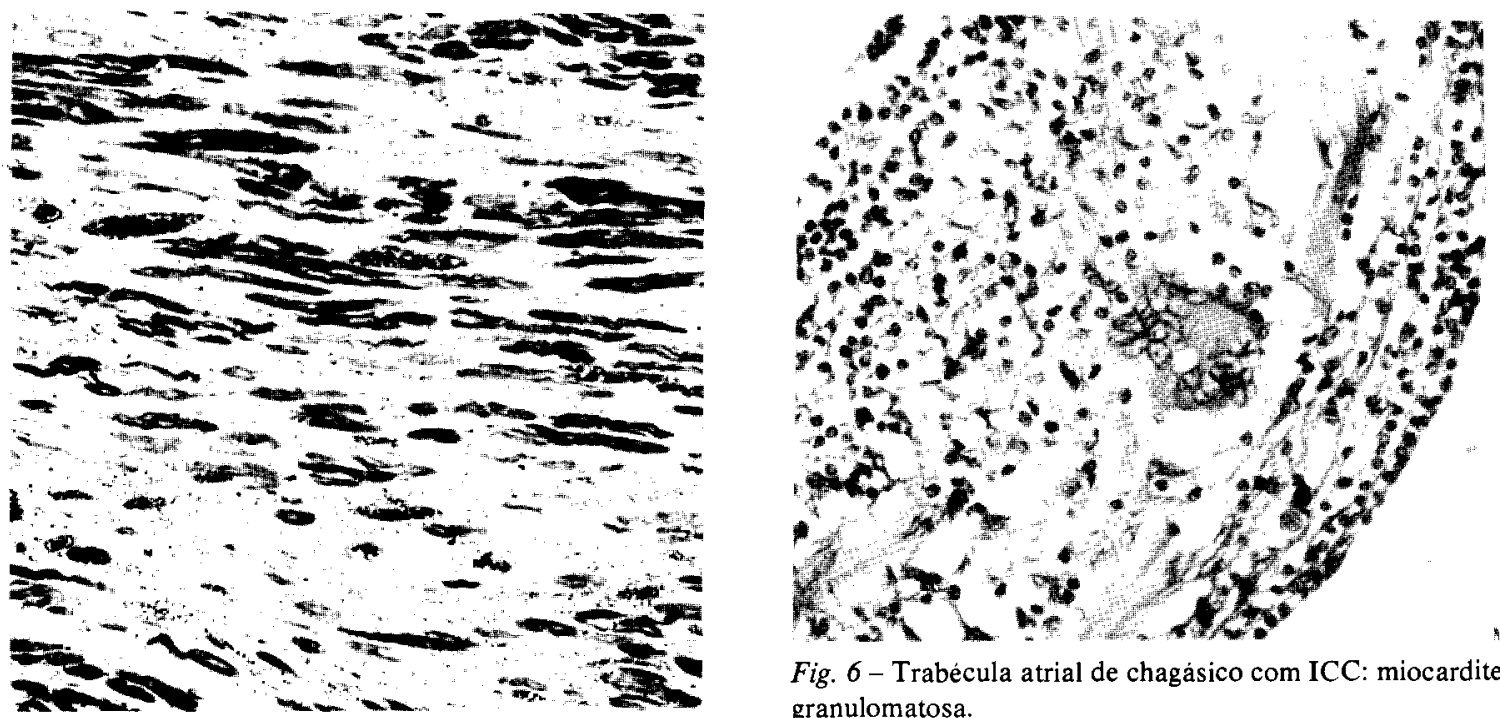

Fig. 5 - Corte de ventrículo de chagásico sem "megas" com

Fig. 6 - Trabécula atrial de chagásico com ICC: miocardite granulomatosa.

ICC de longa duração - (Tricrômico de Gomory x63) miocardite com fibrose exuberante.

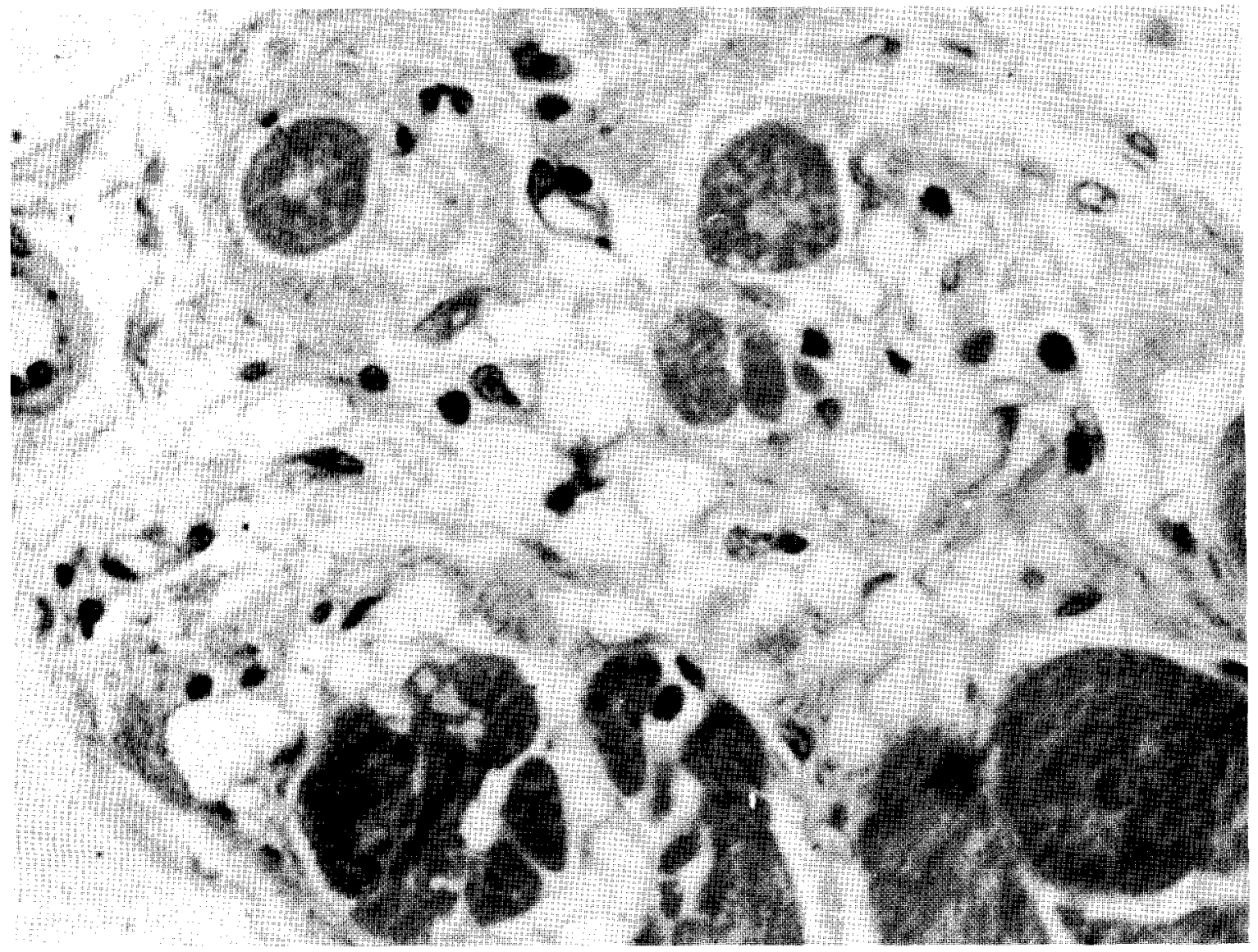

Fig. 7 - Miocárdio ventricular (HE x 400) - Chagásico com ICC de longa duração: foco de "miocitólise" associado a raras células mononucleares. Observa-se ainda material amorfo acidófilo no intersticio. 
Almeida HO, Gobbi H, Teixeira VPA, Araujo WF, Fernandes PA. Aspectos da miocardite em chagásicos crónicos com "megas" e sem "megas" com insuficiència cardiaca congestiva. Revista da Sociedade Brasileira de Medicina Tropical 17: 8188, Abr-Jun, 1984

Tabela 1 - Intensidade do exsudato celular nas câmaras cardiacas em 20 chagásicos com "megas" e em 20 chagásicos com ICC sem "megas".

\begin{tabular}{|c|c|c|c|c|c|c|}
\hline & $\begin{array}{l}\text { Infiltrado } \\
\text { Leucocitário }\end{array}$ & $V D$ & $V E$ & $A D$ & $A E$ & Ponta do VE \\
\hline \multirow{4}{*}{ 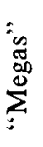 } & Ausente & 6 & 6 & 6 & 11 & 5 \\
\hline & Discreto & 8 & 3 & 10 & 3 & 8 \\
\hline & Moderado & 6 & 11 & 4 & 6 & 6 \\
\hline & Acentuado & 0 & 0 & 0 & 0 & 1 \\
\hline \multirow{4}{*}{ 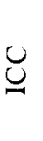 } & Ausente & - & - & - & - & 1 \\
\hline & Discreto & 3 & 2 & 4 & 3 & 3 \\
\hline & Moderado & 8 & 7 & 10 & 10 & 6 \\
\hline & Acentuado & 9 & 11 & 6 & 7 & 10 \\
\hline
\end{tabular}

Tabela 2 - Intensidade da fibrose miocárdica nas câmaras cardiacas em 20 chagásicos com "megas" e em 20 chagásicos com ICC sem "megas".

\begin{tabular}{|c|c|c|c|c|c|c|}
\hline & Fibrose & $V D$ & $V E$ & $A D$ & $A E$ & Ponta do VE \\
\hline \multirow{4}{*}{$\begin{array}{l}\text { con } \\
\sum_{0}^{\infty} \\
\sum_{0}^{\infty}\end{array}$} & Ausente & 11 & 8 & 12 & 13 & 6 \\
\hline & Discreta & 6 & 8 & 5 & 6 & 8 \\
\hline & Moderada & 2 & 4 & 3 & 1 & 2 \\
\hline & Acentuada & 1 & 0 & 0 & 0 & 4 \\
\hline \multirow{4}{*}{ 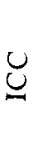 } & Ausente & - & -. & - & - & 1 \\
\hline & Discreta & 1 & - & 3 & 3 & 3 \\
\hline & Moderada & 7 & 5 & 11 & 12 & 4 \\
\hline & Acentuada & 12 & 15 & 6 & 5 & 12 \\
\hline
\end{tabular}

\section{DISCUSSÃO}

Nossos achados, para o coração dos chagásicos que faleceram na vigência de ICC concordam, de modo geral, com as observações de Chagas e cols ${ }^{13}$, Torres 3839 40, Andrade e Andrade ${ }^{9}$, Andrade 7 , Mignone ${ }^{23}$, Anselmi e cols 10 e Almeida ${ }^{1}$. Diferem, porem, das observações de Köberle ${ }^{19}$ e Köberle e $\operatorname{cols}^{20}$, para quem a miocardite seria discreta "tendo pouca importância na patogênese da cardiopatia". Nos chagásicos com ICC a miocardite foi sempre acentuada, com edema miocárdico, fibrose e exsudato leucocitário pronunciados, enquanto os granulomas tipicos com células gigantes foram pouco numerosos. Nos focos inflamatorios destes corações a mastocitose foi freqüente, fato já observado por Almeida e cols ${ }^{3}$. Em contraposição, nos chagásicos com "megas" a miorcadite foi, geralmente, discreta, excepcionalmente com fibrose acentuada, sendo o exsudato pouco intenso e pobre em mastócitos. Nestes chagásicos os "fenômenos regressivos" das miocélulas foram discretos nos focos inflamatorios e, praticamente, ausentes à distância destes. Além de destruir tecido a atividade inflamatória no miocárdio pode exercer importantes efeitos fisiopatológicos através da liberação de seus mediadores quimicos. Baseados nos estudos de Capurro e Levi12 e Levi21, mostrando que a histamina pode produzir diferentes alterações eletrocardiográficas de acordo com o local do coração em que exerce seus efeitos (átrio, ventrículos, nó sinusal, nó átrio-ventricular, etc.), podemos admiti-las como possivel desencadedora de algumas arritmias transitórias que surgem no chagásico crônico. A fibrose miocárdica, pode dificultar a propagação do estímulo e alterar a dinâmica de contração ventricular ${ }^{11} \mathrm{e}$, quando endomisial, dificulta as trocas entre capilar e miocélula 32 .

A miocardite, geralmente discreta e com escassa fibrose, verificada em coraçōes de peso normal ou ligeiramente hipertróficos dos chagásicos com "megas", bem como a inflamação fibrosante e hipertrofia do miocárdio, acentuadas, vistas nos casos de ICC, estão de acordo com as observações de Chapadeiro ${ }^{14}$ mostrando que a hipertrofia do miocárdio ventricular e a fibrose inflamatória correm paralelas no chagásico crônico. De modo semelhante, a "lesão vorticilar esquerda" tem sido admitida como uma das conseqüencias da miocardite por Moia e Rosembaum ${ }^{25}$, Mignone 23 e Anselmi e cols ${ }^{10}$. Em trabalho anterior ${ }^{1}$, após afastar a desnervação, o hemibloqueio anterior esquerdo e a hipóxia como determinantes da lesão vorticilar, mostramos que é a miocardite local, o único fator de responsabilidade da tripanossomose que se associa à referida lesão. Ora, nos chagásicos com "megas" tivemos a oportunidade de confirmar essas observações quando mostramos que a baixa freqüència de lesão apical, está de acordo com a intensidade da miocardite apical que raramente é suficiente para determinar sua formação. Por fim, a ICC parece ser basicamente a resultante final da agressão inflamatória que a tripanossomose determina no coração. Os dados da literatura, associados ao fato de termos observado miocardite ventricular intensa e constante nos chagásicos com ICC e geralmente discreta ou ausentes nos casos de "megas" sem ICC, apesar da desnervação mais acentuada nestes, leva-nos a considerar a cardiopatia chagásica crônica que evolui para insuficiência cardiaca, como uma miocardiopatia inflamatória.

Uma série de estudos tem demonstrado a existência, em chagásicos crônicos, de auto-anticorpos anti-EVI, antinervo, antineurônios 1618222641 e de 
Almeida HO, Gobbi H, Teixeira VPA, Araujo WF, Fernandes PA. Aspectos da miocardite em chagásicos crônicos com "megas" e sem "megas" com insuficiencia cardiaca congestiva. Revista da Sociedade Brasileira de Medicina Tropical 17: 8188, Abr-Jun, 1984

linfócitos $T$ capazes de agredir células miocárdicas "in vitro"33-37 além da formação de imunocomplexos ${ }^{15}$ e de dados que sugerem ativação do complemento ${ }^{29}$. Para Teixeira ${ }^{35}$ e Teixeira e cols ${ }^{36}$, esta resposta auto-imune seria devida à existência de determinantes antigênicos comuns entre tecido cardiaco e o Trypanosoma cruzi. A presença desta autoimunidade, aliada à escassez de parasitas no miocárdio, tem levado alguns estudiosos a admitirem que, após a fase aguda, a agressão cardíaca evoluiria independentemente do parasita. Entretanto apesar de Teixeira admitir que a auto-imunidade seria o determinante da miocardite, acreditamos que se a formação de granulomas e de focos de miocardite que são, até certo ponto, lesões similares, fossem devidas a auto-imunidade, deveriam ser mais abundantes. Estas lesões poderiam ser respostas do organismo contra antígenos parasitários adsorvidos a células miocárdicas próximas a ninhos de amastigotas como admitem Ribeiro dos Santos e Hudson 30 31. Estas lesồes focais podem evoluir para fibrose, deixando pequenas cicatrizes. Como o chagásico leva 10 a 30 anos para descompensar, o somatório das seqüelas destas lesões podem adquirir importância apreciável.

\section{SUMMARY}

The study of 20 hearts from chagasic patients with "megas" and of others 20 from chagasics without "megas" with heart failure, shows that both, myocardial fibrosis and inflammatory exudate are light in cases with "megas" and severe in group with heart failure. In chagasic with "megas" the myocardial hypertrophy, the apical lesion and the cardiac insufficiency are infrequent. Our findings suggest that they are related to the myocardial ventricular inflammation and not to the cardiac denervation. This latter is more severe in cases of "megas" than in cases of congestive heart failure without "megas".

Key words: Chagasic cardiomyopathy. Myocarditis. Megas. Cardiac insufficiency. Pathogenesis.

\section{REFERÊNCIAS BIBLIOGRÁFICAS}

1. Almeida HO. "A lesão vorticilar" da cardiopatia chagásica crônica. Tese de doutoramento. Unniversidade Federal de Minas Gerais, Belo Horizonte, 1978.

2. Almeida HO. A cardiopatia em chagásicos crônicos com e sem "megas". Tese de Professor Titular. Faculdade de Medicina do Triângulo Mineiro, Uberaba, 1982.
3. Almeida HO, Pereira FEL, Tafuri WL. Estudo quantitativo dos mastócitos na cardiopatia chagásica crônica. Revista do Instituto de Medicina Tropical de São Paulo 17: 5-9, 1975.

4. Almeida HO, Teixeira VPA, Araujo WF. Comportamento do peso do coração e do corpo em chagásicos crônicos com e sem "megas". Revista da Sociedade Brasileira de Medicina Tropical 13: 85-89, 1980.

5. Almeida HO, Teixeira VPA, Morais CA, Araujo WF, Gobbi H, Magnani GA, Fernandes PA. Ocorrência de morte súbita e por insuficiência cardíaca congestiva em chagásicos com e sem "megas". Revista Goiana de Medicina (No prelo).

6. Almeida HO, Teixeira VPA, Araujo WF, Gobbi H. Alterações do sistema nervoso autônomo intracardiaco em chagásicos com e sem "megas". Enviado para publicação na Revista Goiana de Medicina.

7. Andrade ZA. Anatomia patológica na doença de Chagas. Revista Goiana de Medicina 4: 103-199, 1958.

8. Andrade ZA. Chagas' disease. Pathology of the cardiac lesions. International Symposium on New Approaches in American Trypanosomiasis Research, Belo Horizonte, 1975.

9. Andrade ZA, Andrade SG. A patologia da doença de Chagas (forma crônica cardiaca). Boletim da Fundação Gonçalo Moniz 6: 1-53, 1955.

10. Anselmi A, Pifano F, Suarez JA, Gurdiel O. Myocardiopathy in Chagas' disease. I. Comparative study of pathologic findings in chronic human experimental Chagas myocarditis. American Heart Journal 72: 469-481, 1966.

11. Bogliolo L. As causas anatômicas da insuficiência cardíaca na cardiopatia chagásica crônica estudadas comparativamente com as causas anatômicas da insuficiência cardiaca noutras cardiopatias. Parte II.Arquivos Brasileiros de Cardiologia 29: 479-483, 1976.

12. Capurro $N$, Levi $R$ Anaphylaxis in the guineapig isolated heart: selective inhibition by burimamide of the positive inotropic and chronotropic effects of the release of histamine. British Journal of Pharmacology 48: 620628, 1973.

13. Chagas C. Sur les alterations du coeur dans la trypanosomiase americaine (maladie de Chagas). Arch. Maladies du Coeur, 1-15, 1928. In: Carlos Chagas Coletânea de trabalhos cientificos. Ed. Universidade de Brasília, 1981.

14. Chapadeiro E. Peso do coração e intensidade do processo inflamatório na cardiopatia chagásica crônica. 
Almeida HO, Gobbi H, Teixeira VPA, Araujo WF, Fernandes PA. Aspectos da miocardite em chagásicos crônicos com "megas" e sem "megas" com insuficiência cardiaca congestiva. Revista da Sociedade Brasileira de Medicina Tropical 17: 8188, Abr-Jun, 1984

Boletin de la Oficina Sanitária Panamericana 63: 236239, 1967.

15. Chaves J, Mariano ON, Souza HBWT, Irulegui I, Vaz CAA. Deposição de complexos imunes na doença de Chagas experimental. Revista do Instituto de Medicina Tropical de São Paulo 24: 11-15, 1982.

16. Cossio PM, Diez C, Szarfman A, Kreutzer E, Candiolo B, Arana RH. Chagasic Cardiopathy. I. Demonstration of a serum gamma globulin factor which reacts with endocardium and vascular structures. Circulation 49: 13-21. 1974.

17. Cossio PM, Laguens RP, Diez C, Szarfman A, Segal A, Arana RH. Chagasic cardiopathy: antibodies reacting with the plasma membrane of striated muscle and endothelial cells. Circulation 50: 1252-1259, 1974.

18. Khoury EL, Ritacco V, Cossio PM, Languens RP, Szarfman A, Diez C, Arana RH. Circulating antibodies to peripheral nerve in American Trypanosomiasis (Chagas' disease). Clinical and Experimental Immunology 26: 8 -15, 1979

19. Köberle F. Cardiopatia chagásica. O Hospital 53: 311 $346,1958$.

20. Köberle F, Costa RB, Oliveira JAM, Oliveira JSM Patologia da moléstia de Chagas. Medicina (C.A.R.L.) 1: 5-45, 1972.

21. Levi R. Effects of exogenous and immunologically released histamine on the isolated heart: a quantitative comparison. Journal of Pharmacology and Experimental Therapy 182: 227-238, 1972.

22. Marquez JO. Imunopatologia do líquido cefalorraqueano na doença de Chagas. Tese de Doutoramento. Faculdade de Medicina de Ribeirão Preto, 1979.

23. Mignone C. Alguns aspectos da anatomia patológica da cardite chagásica crônica. Tese de Professor Catedrático. Faculdade de Medicina, Universidade de São Paulo, São Paulo, 1958.

24. Miziara LJ, Almeida HO, Teixeira VPA, Calil LC, Almeida JA. Alterações cardiacas em pacientes chagásicos crônicos com e sem "megas". Arquivos Brasileiros de Cardiologia 35: 197-199, 1980.

25. Moia B, Rosembaum MB, Hojman D. Aneurismas ventriculares en la miocarditis crónica chagásica. Revista Argentina de Cardiologia. 22: 113-150, 1955.

26. Peralta JM, Manigot DA, Muscelli EOA, Magalhães TCR, Almeida EA, Bastos A. Anticorpos EVI e NP na infeç̧ão chagásica crônica. Estudo em pacientes com diferentes formas clínicas. Revista do Instituto de $\mathrm{Me}$ dicina Tropical de São Paulo 24: 6-10, 1982.
27. Prata A. Relação etiológica entre doença de Chagas e megaesôfago. Anais do Congresso Internacional de Doença de Chagas 4: 1317, 1963.

28. Rezende JM, Rassi A. Comprometimento do esôfago na molestia de Chagas. Megaesôfago e cardiopatia. $O$ Hospital 53: 9, 1959.

29. Riera NE, Malbran A, Ritacco V, Cossio PM, Arana RM, Bracco MME. El sistema complemento en la enfermedad de Chagas crônica. Medicina (Buenos Aires) 40:125-132, 1980 .

30. Ribeiro dos Santos R, Hudson L. Trypanosoma cruzi: Adsorption of parasite antigens to mammalian cell surfaces. Parasite Immunology 2: 1-10, 1980.

31. Ribeiro dos Santos R, Hudson L. Trypanosoma cruzi: Immunological consequences of parasite modification of host cells. Clinical and Experimental Immunology 40: 36-47, 1980.

32. Tafuri WL. Alterações ultra-estruturais dos componentes muscular, intersticial e nervoso do coração, esôfago e intestinos na doença de Chagas experimental e humana. Tese. Faculdade de Medicina da Universidade Federal de Minas Gerais, Belo Horizonte, 1974.

33. Teixeira ARL. Evidência de imunidade na doença de Chagas. O papel da imunidade celular. Revista Goiana de Medicina, 23: 15-22, 1977.

34. Teixeira ARL. Competencia imunológica do paciente chagásico. Tese. Faculdade de Ciências da Saude, Universidade de Brasilia, 1979.

35. Teixeira ARL. Patogenia da doença de Chagas. Jornal Brasileiro de Medicina 3: 23-33, 1980.

36. Teixeira ARL, Teixeira G, Macedo V, Prata A. Trypanosoma cruzi - sensitized T-lymphocyte mediated ${ }^{51} \mathrm{Cr}$ release from human heart cells in Chagas' disease. American Journal of Tropical Medicine and Hygiene 27: 1097-1107, 1978.

37. Teixeira ML, Rezende Filho J, Figueiredo F, Teixeira ARL. Chagas' disease: selective affinity and cytotoxicity of $T$. cruzi immune lymphocytes to parasympathetic ganglion cells. Memórias do Instituto Oswaldo Cruz 75 33-45, 1980.

38. Torres CBM. Miocitólise e fibrose do miocárdio na doença de Chagas. Memórias do Instituto Oswaldo Cruz 58: 161-182, 1960.

39. Torres CBM. Sobre a anatomia patológica da doença de Chagas. Memórias do Instituto Oswaldo Cruz 36: 391 $404,1941$. 
Almeida HO, Gobbi H, Teixeira VPA, Araujo WF, Fernandes PA. Aspectos da miocardite em chagásicos crónicos com "megas" e sem "megas" com insuficiencia cardiaca congestiva. Revista da Sociedade Brasileira de Medicina Tropical 17: 81 88, Abr-Jun, 1984

40. Torres CBM. Patogenia das lesôes do miocárdio na doença de Chagas. Revista Goiana de Medicina 5: 177 $183,1959$.

41. Trezza E. Anticorpos antimiocárdio demonstrados por imunofluorescência indireta no soro de portadores de doença de Chagas crônica. Correlação entre os resultados sorológicos e as alterações eletrocardiográficas. Tese. Faculdade de Medicina. Universidade Estadual Paulista, Botucatu, 1972. 